\title{
Is Long Term Creatine and Glutamine Supplementation Effective in Enhancing Physical Performance of Military Police Officers?
}

\author{
by \\ Celismar Lázaro da Silveira 1, Thiago Siqueira Paiva de Souza ${ }^{3,4}$, \\ Gilmário Ricarte Batista 3,4, Adenilson Targino de Araújo 1,3,4, \\ Júlio César Gomes da Silva 3,4, Maria do Socorro Cirilo de Sousa 2,3,4, \\ Carlos Marta 5,6, Nuno Domingo Garrido 1,2
}

The objective of this study was to analyze the effect of supplementation with creatine and glutamine on physical fitness of military police officers. Therefore, an experimental double blind study was developed, with the final sample composed by 32 men randomly distributed into three groups: a group supplemented with creatine ( $n=10)$, glutamine ( $n=10)$ and a placebo group $(n=12)$ and evaluated in three distinct moments, in an interval of three months (T1, T2 and T3). The physical training had a weekly frequency of 5 sessions $x 90$ min, including strength exercises, local muscular resistance, flexibility and both aerobic and anaerobic capacity. After analyzing the effect of time, group and interaction (group $x$ time) for measures that indicated the physical capabilities of the subjects, a significant effect of time for the entire variable was identified $(p<0,05)$. However, these differences were not observed when the univaried intragroups and intergroups analysis was performed $(p>0,05)$. In face of the results it was concluded that supplementation with creatine and glutamine showed no ergogenic effect on physical performance in military police officers.

Key words: supplementation, exercise, creatine, glutamine, RCT, military police officers.

\section{Introduction}

Using nutritional supplements to increase physical performance is, nowadays, a much highlighted strategy in physically active individuals (Maughan and Burke, 2004). Among the numerous supplements commercialized in the market today, it is possible to find creatine $(\mathrm{Cr})$ and glutamine $(\mathrm{Gl})$, which had their ergogenic action tested and were proved to increase levels of muscular strength and power along with resistance training (Wright et al., 2007; Terjung et al., 2000; Bemben and Lamont, 2005; Gualano et al., 2008).

Although data about long term supplementation is scarce (particularly in athletes), the literature refers to several well controlled research projects, indicating that supplementation with creatine (ACSM, 2000; Kreider, 1997; Volek et al., 1999) and glutamine

\footnotetext{
1 - Department of Sport Sciences, University of Trás-os-Montes and Alto Douro, Vila Real, Portugal.

2 - Research Centre for Sport, Health and Human Development, Vila Real, Portugal.

3 - Kinanthropometry and Human Development Laboratory - LABOCINE -UFPB, João Pessoa / PB, Brazil.

4 - Associate Programme on Graduate Program in Physical Education UPE / UFPB, João Pessoa, Paraíba, Brazil.

5 - Department of Sport Sciences, Polytechnic Institute of Guarda (IPG, Guarda, Portugal).

6 - Research Unit for Inland Development (UDI, Portugal).
} 
(Antonio et al., 1999; Ziegler et al., 1990) is safe, as long as done carefully and by professionals.

Although many studies were performed with these supplements, it is still not clear if the long term use of glutamine or creatine affects positively protein synthesis, body composition, anaerobic power and other physiological variables (Fontana, 2006).

The monohydrated creatine $(\mathrm{Crm})$ is widely used, above all, by athletes and physically active individuals, due to its possible ergogenic effects on muscular mass and anaerobic physical performance (Mendes et al., 1999; Mihic et al., 2000). Therefore, it is suggested that an increase in muscular concentration of total creatine ( $\mathrm{CrT}$ ) and phosphocreatine (CP), induced by supplementation with monohydrate creatine (Crm), can increase the availability of $\mathrm{CP}$ and, consequently, accelerate the rate of re-synthesis of ATP during intermittent anaerobic exercise, enhancing physical performance in this type of exercise. (Balsom et al., 1995; Febbraio et al., 1995; Maganaris and Maughan, 1998).

Glutamine is a crucial amino acid for the human body, with functions that include its use as fuel for the cells of the immune system, together with isoleucine, valine and leucine being more abundant in muscle tissue, having bigger energetic and metabolic importance (Ceddia et al., 2000; Newsholme et al., 2003).

The literature indicates that glutamine is efficient in increasing the absorption of electrolytes and water in animals (Nath et al., 1992; Van Loon et al., 1996). Both glutamine and alanine, important amino acids for the human body, have been proved efficient for antioxidant defense during serious diseases (Abilés et al., 2008; Kumar and Anandan, 2007). Glutamine has been reclassified from dispensable amino acids to a conditionally indispensable amino acid for the homeostatic functions of the organism (Rogero and Tirapegui, 2003).

Based on the aforementioned studies, according to Military Physical Training (MPT) which is an exercise program that has a principle of specificity and that seeks to improve the physical qualities that are most sought in the labor activities of this profession, in which muscular strength and endurance of the individual are prerequisites for efficient performance. Currently, ergogenic means can be used with police students to minimize fatigue caused by high volume of training and improve their physical fitness. This study examined the effect of supplementation with creatine and glutamine on physical performance of military police officers.

\section{Material and Methods}

\section{Participants}

The research was an experimental randomized control trial, with a non probabilistic sample process and longitudinal approach. Military police officers from the Estate of Tocantins-Brazil, physically active and apparently healthy, participated in the study. The research applied a double blind model with random distribution of subjects to the creatine, glutamine and placebo groups.

In order to select the sample we used a calculation based on the mistake of estimation $\alpha$ by $5 \%$, estimative of the size of the effect of 0,5 , the power $\beta$ of $86 \%$ and level of reliability by $95 \%$ through the statistic software Gpower, performing a number of 36 subjects, who were randomly divided into three groups: one that received supplementation with creatine $(\mathrm{GCr}$, $\mathrm{n}=12$ ), other with glutamine (GGL, $\mathrm{n}=12$ ) and a placebo group (GPL, $\mathrm{n}=12$ ).

All the participants signed the Term of Free and Clarified Consent, after being informed about the procedures of the research. The study was approved by the Committee of Ethics in Research, registered under the number 0312/2011, in accordance with the ethical principles contained in the Declaration of Helsinki

To be included in the study the following criteria were established: age between 18 and 30; non smoking; no alcohol drinking; no anabolic steroids use; no nutritional supplements of any kind; moreover, the participants had to answer negatively to all the items of the Physical Activity Readiness Questionnaire (PAR-Q).

The final sample was composed by 32 subjects $(\mathrm{GCr}=10$; $\mathrm{GGL}=10$; $\mathrm{GPL}=12)$, the others were excluded for not being able to perform the physical tests $(n=2)$, and for being absent in the days of the evaluations due to health problems $(\mathrm{n}=2)$.

\section{Procedures}

The evaluations were performed on premises of the Military Police Academy. The groups were evaluated in three distinct moments, 
within a three months period: at the beginning of the activities (T1); after six weeks of activities (T2); and after twelve weeks of activities (T3).

MPT was performed five times per week with duration of $90 \mathrm{~min}$. Each training session included three parts: a warm up and stretching; physical exercises; and a cool down. The exercises were a mix of neuromuscular and cardiopulmonary training. The activities were supervised by specialists and totally fulfilled under the same military context. Supplementation was given under the supervision of a nutritionist. The creatine and glutamine supplementation protocols were based on previously confirmed scientific data (Cox et al., 2002; Deutekom et al., 2000; Edwards et al., 2000; Okudan and Gokbel, 2005).

The supplements of glutamine, creatine and placebo (cornflour) were given orally, dissolved in a medium sweet liquid (150 to 300 $\mathrm{ml}$ ). The adaptation dose (first week) from 0,3 $\mathrm{g} \cdot \mathrm{kg}^{-1}$, was divided into three equal daily doses distributed along the day, and the maintenance dose (about 12 weeks) by $0,03 \mathrm{~g} \cdot \mathrm{kg}^{-1}$ in a unique dose, $30 \mathrm{~min}$ after MPT. All the supplements were given in sachets. The ingestion of the supplements took place in the morning at 6:30 am, before the beginning of the MPT activities, for 93 days without interruption.

\section{Measures}

To verify the effect of supplementation on physical performance of military policemen, as well as aerobic and anaerobic capacity, muscular strength of upper and lower limbs, flexibility and local muscle endurance tests were used.

The aerobic capacity was evaluated by the 12 minute Cooper test (1968); the anaerobic capacity was evaluated by the shuttle run test; muscle strength of the upper limbs was evaluated by pushups (Mayhew, 1991); and muscle strength of the lower limbs was evaluated by the horizontal jump (Scott and Docherty, 2004); flexibility was determined by the sit and reach test (ACSM, 2010); and abdominal muscle endurance was evaluated by the sit-up test (Sarti et al., 1996). In order not to compromise the study reliability, physical tests were performed by only one researcher.

\section{Statistical Analysis}

Windows version 20.0. The values were expressed as means and standard deviation (SD). Before performing the inferential analysis, for numeric variables, the assumption of homogeneity was tested by the Levene's test and the sphericity was tested by the Mauchly's test whereas for the absence of the sphericity the correction of Greenhouse-Geiser was adopted. An Anova one way, with the Tuckey HSD post hoc test, was used to check possible differences among the groups, for each phase of the data collection, as well as the possible alterations between the measures. A two way Anova was performed to check the time effect (measures: T1 x T2 x T3), the group effect (placebo $x$ creatine $x$ glutamine) and the time $x$ group interaction, for the variables of physical performance. Additionally the respective delta of variation $(\% \Delta)$ was presented between the first and the second $(\% \Delta 1)$, and between the second and the third $(\% \Delta 2)$ measurements. The effect size was calculated based on Cohen's (1988) criteria. It was considered small if $0 \leq 1 \mathrm{dl} \leq 0.2$, medium if $0.2 \leq l \mathrm{dl} \leq 0.5$, and large if $\mathrm{ldl}>0.5$. The level of significance was set at $\alpha=0.05$.

\section{Results}

Table 1 presents the multivariated analysis of the variable of physical performance. A significant effect was identified in time for the entire variable analysed. Table 2 presents the descriptive and univariate analysis of the variables of physical performance in the groups GCr, GGL and GPL. The aerobic capacity (VO2) presented differences between $\mathrm{T} 1$ vs $\mathrm{T} 2$ and $\mathrm{T} 1$ vs T3, mainly from the T1 for the T2, for the GPL (\% $\Delta 1=13)$ and GGL $(\% \Delta 1=12)$, given the measures were different for the GPL $(F=8,657, p=0,001)$, with alterations between $\mathrm{T} 1 \mathrm{vs} \mathrm{T} 2(\mathrm{p}=0,002)$ and T1 vs T3 $(0,004)$, and for the GGL $(\mathrm{F}=5,623, \mathrm{p}=$ $0,009)$, with significant post hoc for T1 vs T2 ( $p=$ $0,018)$ and T1 vs T3 ( $p=0,021)$.

The anaerobic capacity (Shuttle-Run), presented differences in the following times: GPL ( $F=8,109, p=0,001$, post hoc T1 vs T2 $p=0,018$ and T1 vs T3 $p=0,001)$; for the GCr ( F = 19,791, p $=0,001$, post hoc T1 vs T2 $p=0,001$ and T1 vs T3 $p$ $=0,001)$, and for the GGL $(\mathrm{F}=27,088, \mathrm{p}=0,001$, post hoc $\mathrm{T} 1$ vs $\mathrm{T} 2 \mathrm{p}=0,001$ and $\mathrm{T} 1$ vs $\mathrm{T} 3 \mathrm{p}=$ $0,001)$

Muscle endurance of the abdomen (RML_ABD) presented differences in the 
following measurements points: GPL ( $\mathrm{F}=47,185$, $\mathrm{p}=0,001$; post hoc T1 vs T2, $\mathrm{p}=0,001$; T1 vs T3, $\mathrm{p}=$ $0,001)$, GCr ( $\mathrm{F}=44,738, \mathrm{p}=0,001$; post hoc $\mathrm{T} 1$ vs T2, $\mathrm{p}=0,001$; T1 vs T3, 0,001) GGL ( $\mathrm{F}=29,533, \mathrm{p}=$ 0,001 ; post hoc T1 vs T2, $\mathrm{p}=0,001$; T1 vs T3, $\mathrm{p}=$ $0,001)$.

Muscle strength (MS) presented differences in the following measurements points: GPL $(\mathrm{F}=$ 30,984, $\mathrm{p}=0,001$; post hoc $\mathrm{T} 1$ vs $\mathrm{T} 2, \mathrm{p}=0,015$; T1 vs T3, p =0,001; T2 vs T3, p=0,001). GCr $(F=$ $58,391, \mathrm{p}=0,001$; post hoc $\mathrm{T} 1$ vs T2, $\mathrm{p}=0,001$; T1 vs T3, $\mathrm{p}=0,001$; T2 vs T3, $\mathrm{p}=0,001)$; GGL $(\mathrm{F}=$ 9,664, $\mathrm{p}=0,001$; post hoc T1 vs T2, $\mathrm{p}=0,001$ ).

Muscle strength (MS) and flexibility did not show differences between times. For the between group analysis there were no differences for the measures of $\mathrm{T} 1, \mathrm{~T} 2$ and $\mathrm{T} 3$, which did not indicate effect of the group, as well as the interaction among groups and time.

\section{Discussion}

The main objective of this study was to evaluate the ergogenic effects of creatine and glutamine supplementation on physical performance of military police officers. All tests and measurements, sample implementation and internal consistency were high, and performed according to protocols validated by the literature. The follow-up period (three months), may not have caused the expected effects of the supplementary intervention on the dependent variables. The one which presented a high size effect $\left(\eta^{2}>0.80\right)$, was aerobic capacity $\left(\mathrm{VO}_{2}\right)$.

\section{Table 1}

Multivaried analysis of the variables of the physical performance $(n=32)$

\begin{tabular}{|c|c|c|c|c|c|c|}
\hline \multirow[b]{2}{*}{ Statistic Effect } & \multicolumn{3}{|c|}{$\mathrm{VO} 2(\mathrm{ml} / \mathrm{kg} / \mathrm{min}) \ddagger$} & \multicolumn{3}{|c|}{ Shuttle Run (s)‡ } \\
\hline & $\mathrm{F} / \mathrm{p}$-value ${ }^{\varepsilon}$ & $\eta^{2}$ & post hoc & $\mathrm{F} / \mathrm{p}$-value & $\eta^{2}$ & post hoc \\
\hline Time $(\mathrm{T})$ & $117,608^{*}$ & 0.80 & $\mathrm{~T} 1 \neq \mathrm{T} 2 \quad \mathrm{~T} 1 \neq \mathrm{T} 3$ & $115,421^{*}$ & 0.80 & $\mathrm{~T} 1 \neq \mathrm{T} 2 \quad \mathrm{~T} 1 \neq \mathrm{T} 3 \quad \mathrm{~T} 2 \neq \mathrm{T} 3$ \\
\hline Group (G) & 0,446 & 0.03 & - & 0,144 & 0.01 & - \\
\hline \multirow[t]{2}{*}{ Interaction $T$ x G } & 3,612 & 0.20 & - & 0,628 & 0.04 & - \\
\hline & \multicolumn{3}{|c|}{$\left.\mathrm{SH}_{(\mathrm{cm})}\right)^{\ddagger}$} & \multicolumn{3}{|c|}{ FB (rep) $)^{\ddagger}$} \\
\hline Statistic Effect & $\mathrm{F} / \mathrm{p}$-value & $\eta^{2}$ & post hoc & $\mathrm{F} / \mathrm{p}$-value & $\eta^{2}$ & post hoc \\
\hline Time (T) & $10,847^{*}$ & 0.30 & $\mathrm{~T} 1 \neq \mathrm{T} 2 \quad \mathrm{~T} 1 \neq \mathrm{T} 3$ & $153,910^{*}$ & 0.80 & $\mathrm{~T} 1 \neq \mathrm{T} 2 \quad \mathrm{~T} 1 \neq \mathrm{T} 3 \quad \mathrm{~T} 2 \neq \mathrm{T} 3$ \\
\hline Group (G) & $0,448(p>0,05)$ & 0.03 & - & 0,984 & 0.05 & - \\
\hline \multirow[t]{2}{*}{ Interaction $\mathrm{T}$ x G } & $0,188(p>0,05)$ & 0.01 & - & 2,495 & 0.10 & - \\
\hline & \multicolumn{3}{|c|}{ RML_ABD(rep) $)^{\ddagger}$} & \multicolumn{3}{|c|}{ Flexibility $(\mathrm{cm})^{\ddagger}$} \\
\hline Statistic Effect & $\mathrm{F} / \mathrm{p}$-value & $\eta^{2}$ & post hoc & $\mathrm{F} / \mathrm{p}$-value ${ }^{\varepsilon}$ & $\eta^{2}$ & post hoc \\
\hline Time $(\mathrm{T})$ & $308,132 *$ & 0.90 & $\mathrm{~T} 1 \neq \mathrm{T} 2 \quad \mathrm{~T} 1 \neq \mathrm{T} 3 \quad \mathrm{~T} 2 \neq \mathrm{T} 3$ & $37,254^{*}$ & 0.60 & $\mathrm{~T} 1 \neq \mathrm{T} 2 \quad \mathrm{~T} 1 \neq \mathrm{T} 3 \quad \mathrm{~T} 2 \neq \mathrm{T} 3$ \\
\hline Group (G) & 0,904 & 0.05 & - & 0,693 & 0.04 & - \\
\hline Interaction $T \times G$ & 1,600 & 0.10 & - & 0,746 & 0.04 & - \\
\hline \multicolumn{7}{|c|}{$\begin{array}{c}R M L_{-} A B D-\text { Abdominal muscle endurance; } S H \text { - strength of the lower limbs; } \\
F B-\text { strength of the upper limbs. } \\
\text { *Variable that presented effect in the time; } \\
{ }^{\varepsilon} \text { The correction of Greenhouse-Geisserthe was adopted; } p<0,05 .\end{array}$} \\
\hline
\end{tabular}


Table 2

Descriptive and univariated analysis of the variables of physical performance in the groups supplemented with creatine $(C R, n=10)$, glutamine

$(G L, n=10)$ and placebo $(P L, n=12)$ before, during and after the intervention

\begin{tabular}{|c|c|c|c|c|c|}
\hline & $\begin{array}{c}\text { Beginning } \\
\text { (T1) } \\
\mathrm{M} \pm \mathrm{DP}\end{array}$ & $\begin{array}{c}6 \text { weeks } \\
(\mathrm{T} 2) \\
\mathrm{M} \pm \mathrm{DP}\end{array}$ & $\begin{array}{c}12 \text { weeks } \\
\text { (T3) } \\
\mathrm{M} \pm \mathrm{DP}\end{array}$ & $\begin{array}{c}\% \Delta 1 \\
(\mathrm{~T} 2-\mathrm{T} 1)\end{array}$ & $\begin{array}{c}\% \Delta 2 \\
(\mathrm{~T} 3-\mathrm{T} 2)\end{array}$ \\
\hline \multicolumn{6}{|l|}{$\mathrm{VO}_{2}(\mathrm{ml} / \mathrm{kg} / \mathrm{min})$} \\
\hline Placebo & $46,94 \pm 4,55^{\mathrm{a}, \mathrm{b}}$ & $53,18 \pm 3,9$ & $52,82 \pm 3,87$ & 13,3 & $-0,7$ \\
\hline Creatine & $48,26 \pm 4,46$ & $52,15 \pm 4,05$ & $51,27 \pm 3,43$ & 8,1 & $-1,7$ \\
\hline Glutamine & $48,36 \pm 5,12$ & $54,15 \pm 4,47$ & $54,02 \pm 3,46$ & 12,0 & $-0,2$ \\
\hline \multicolumn{6}{|l|}{ Shuttle Run } \\
\hline \multicolumn{6}{|l|}{ (s) } \\
\hline Placebo & $9,87 \pm 0,48^{a, b}$ & $9,39 \pm 0,37$ & $9,22 \pm 0,42$ & $-4,9$ & $-1,8$ \\
\hline Creatine & $9,89 \pm 0,25 \mathrm{a}, \mathrm{b}$ & $9,26 \pm 0,35$ & $9,15 \pm 0,24$ & $-6,4$ & $-1,2$ \\
\hline Glutamine & $9,91 \pm 0,28 \mathrm{a}, \mathrm{b}$ & $9,28 \pm 0,29$ & $9,11 \pm 0,17$ & $-6,4$ & $-1,8$ \\
\hline \multicolumn{6}{|l|}{ RML_ABD } \\
\hline \multicolumn{6}{|l|}{ (rep) } \\
\hline Placebo & $38,91 \pm 5,79 a, b$ & $58,75 \pm 5,15$ & $62,91 \pm 4,75$ & 51,0 & 7,1 \\
\hline Creatine & $41,6 \pm 4,74 \mathrm{a}, \mathrm{b}$ & $60,6 \pm 4,81$ & $62,8 \pm 4,73$ & 45,7 & 3,6 \\
\hline Glutamine & $40,8 \pm 7,13 \mathrm{a}, \mathrm{b}$ & $56,20 \pm 4,58$ & $60,1 \pm 5,82$ & 37,7 & 6,9 \\
\hline \multicolumn{6}{|l|}{$\mathrm{SH}_{(\mathrm{cm})}$} \\
\hline Placebo & $227,41 \pm 22,1$ & $235 \pm 23,76$ & $235,33 \pm 20,59$ & 3,3 & 0,1 \\
\hline Creatine & $223,1 \pm 14,65$ & $229,9 \pm 15,57$ & $229,3 \pm 17,0$ & 3,0 & $-0,3$ \\
\hline Glutamine & $218,3 \pm 18,28$ & $228,6 \pm 24,76$ & $228,3 \pm 21,46$ & 4,7 & $-0,1$ \\
\hline \multicolumn{6}{|l|}{ FB (rep) } \\
\hline Placebo & $38,41 \pm 7,19 \mathrm{a}, \mathrm{b}, \mathrm{c}$ & $47,41 \pm 6,73$ & $62,16 \pm 8,36$ & 23,4 & 31,1 \\
\hline Creatine & $36,6 \pm 5,44 \mathrm{a}, \mathrm{b}, \mathrm{c}$ & $48,6 \pm 3,65$ & $56,7 \pm 3,09$ & 32,8 & 16,7 \\
\hline Glutamine & $42,2 \pm 10,43^{b}$ & $51,60 \pm 7,74$ & $59,4 \pm 7,8$ & 22,3 & 15,1 \\
\hline \multicolumn{6}{|l|}{ Flexibility } \\
\hline Placebo & $31,5 \pm 6,41$ & $32,91 \pm 5,35$ & $34,9 \pm 5,59$ & 4,5 & 6,1 \\
\hline Creatine & $34,4 \pm 6,71$ & $36,2 \pm 6,3$ & $37,9 \pm 7,12$ & 5,2 & 4,7 \\
\hline Glutamine & $31,5 \pm 9,72$ & $31,8 \pm 9,54$ & $34,9 \pm 8,76$ & 1,0 & 9,7 \\
\hline
\end{tabular}

Vo2, - aerobic capacity; Shuttle Run - anaerobic capacity;

RML_ABD - Abdominal muscular endurance; SH - strength of the lower limbs;

FB - strength of the upper limbs;

intragroups significant between: ${ }^{a T 1}$ e T2; ${ }^{b T 1}$ e T3; cT2 e T3.

It was proposed as the hypothesis of this study that supplementation with creatine and glutamine would improve physical performance of military officers after three months of physical training, as muscle strength and power benefit with the consumption of these supplements (Wright et al., 2007; Terjung et al., 2000; Bemben and Lamont, 2005; Gualano et al., 2008). However, in this study, supplementation with creatine and glutamine did not confirm an ergogenic effect, as there were no significant differences observed in the two groups taking supplements.

These results corroborate with the findings of Bemben and Lamont (2005) which examined American Football athletes during 9 weeks of training using fartlek, Interval training and plyometrics, and no significant changes between the experimental group (using creatine) and the placebo group were observed. Furthermore, Fontana (2006), in a study with 32 male and healthy subjects, aged $21,7 \pm 2,9$ years, volunteers, divided into three groups (placebo, supplemented with glutamine and supplemented with creatine), after 8 weeks of training that consisted of 4 sessions per week lasting 1,5 h each, did not observe any differences among the groups in the following variables: maximum power, medium power and fatigue. 
According to the study of Buck et al. (2003), with 32 military male subjects aged 19 to 26, divided into three groups (control, supplemented with creatine and supplemented with creatine and maltodextrin), who performed a series of physical activity drills, and it was observed that the dose of monohydrate creatine did not cause significant ergogenic effects on physical performance, represented by the following variables: explosive strength, local muscle strength and anaerobic power.

This suggests that military physical training (MPT) conducted in this study, was dependent on the anaerobic or aerobic power, especially taking into consideration that, according to Williams et al. (2000), there is no association between the improvement in performance of these components and supplementation with creatine. Based on the results of this work, it was concluded that supplementation with glutamine cannot be associated with the improvements in performance in dependent tasks of anaerobic and aerobic power.

However, supplementation with creatine seems to be more effective in endurance exercise, characterized by a high aerobic component, intermittent stimulus of high intensity and short duration (ACSM, 2010). Moreover, there are anaerobic moments in which the speed and intensity of the activity are increased, as at the end of competitions of longer duration when the increased reserve of muscular phosphocreatine can provide a better performance for the athlete. Such associations are observed in military physical training. Glutamine has been frequently associated with improvements of the immune system, reducing the frequencies of occurrence of infections in the respiratory tract.

\section{Conclusion}

The three months supplementation with creatine and glutamine in MPT did not show ergogenic effects on the following variables: aerobic capacity, anaerobic capacity, muscular strength in the upper and lower limbs, flexibility and local muscle endurance.

Further research focusing on MPT is required. Therefore, it is necessary to include a longer period of physical preparation, quantity of repeated measures and standardization of activities which allows a better control of the intensity. The inclusion of the subjective scale of effort perception is suggested, thus allowing the assessment and control of the training program.

\section{References}

Abilés J, Moreno-Torres R, Moratalla G, Castaño J, Abúd RP, Mudarra A, Machado MJ, Planells E, Pérez de la Cruz A. Effects of supply with glutamine on antioxidant system and lipid peroxidation in patients with parenteral nutrition. Nutr Hosp, 2008; 23(4): 332-339

American College of Sports Medicine. ACSM's Health-Related Physical Fitness Assessment Manual. $3^{\text {rd }}$ ed. Philadelphia; 2010

American College of Sports Medicine. The physiological and health effects of oral creatine supplementation. Med Sci Sports Exerc, 2000; 32(3): 706-717

Antonio J, Street C. Glutamine: a potentially useful supplement for athletes. Can J Appl Physiol, 1999; 24(1): 114

Balsom P, Soderlund K, Sjodin B, Ekblom B. Skeletal muscle metabolism during short duration high-intense exercise: influence of creatine supplementation. Acta Physiol Scand, 1995; 115(3): 303-10

Bemben MG, Lamont HS. Creatine supplementation and exercise performance. Sports Med, 2005; 35(2): 107125

Buck KH, Dantas EHM, Silva EB. The lnfluence ofMonohydrated Creatine lntake in the Physical Performance of Military Subjects in Continuous Combat Operations. Fitness \& Performance Journal, 2003; 2(1): 11-16

Ceddia RB, William WN, Lima FB, Flandin P, Curi R, Giacobino JP. Leptin stimulates uncoupling protein-2 mRNA expression and Krebs cycle activity and inhibits lipid synthesis in isolated rat white adipocytes. Eur J Biochem, 2000; 267: 5952-5958 
Cooper KH. A means of assessing maximal oxygen intake: Correlation between field and treadmill testing. JAMA, 1968; 203: $201-204$

Cox G, Mujika I, Tumilty D, Burke L. Acute creatine supplementation and performance during a field test simulating match play in elite female soccer players. Int J Sport Nutr Exe, 2002; 12: 33-46

Deutekom M, Beltman JGM, Ruiter CJ, Koning JJ, Haan A. No acute effects of short-term creatine supplementation on muscle properties and sprint performance. Eur J Appl Physiol, 2000; 82: 223-229

Edwards MR, Rhodes EC, McKenzie DC, Belcastro AN. The Effect of Creatine Supplementation on Anaerobic Performance in Moderately Active Men. J Strength Cond Res, 2000; 14(1): 75-79

Febbraio MA, Flanagan TR, Snow RJ, Zhao S, Carey MF. Effect of creatine supplementation on intramuscular $\mathrm{TCr}$, metabolism and performance during intermittent, supramaximal exercise in humans. Acta Physiol Scand, 1995; 155(4): 387-395

Fontana KE. Effects of resistive exercise associated with creatine or glutamine supplementation in anaerobic power. R Bras Ci e Mov, 2006; 14(3): 79-86

Gualano B, Benatti FB, Ferreira JCB, Franchini E, Brum PC, Lancha Jr, AH. Effects of creatine supplementation on high-intensity intermittent exercise: discrepancies and methodological appraisals. Rev Bras Cineantropom Desemp Hum, 2008; 10(20): 189-196

Kreider RB. Creatine supplementation, analysis of ergogenic value, medical safety, and concerns. J Exerc Physiol Online [on line], 1997; 1: 7-18

Kumar HS, Anandan R. Biochemical studies on the cardioprotective effect of glutamine on tissue antioxidant defense system in isoprenalineinduced myocardial infarction in rats. J Clin Biochem Nutr, 2007; 40: 4955

Maganaris CN, Maughan RJ. Creatine supplementation enhances maximum voluntary isometric force and endurance capacity in resistance trained men. Acta Physilogica, 1998; 163(3): 279-287

Maughan RJ, Burke LM. Nutrição esportiva: manual de ciência e medicina esportiva. Porto Alegre: Artmed; 2004

Mayhew J, Ball T, Arnold M, Bowen J. Push-ups as a measure of upper body strength. J Strength Cond Res, 1991; 5(1): 16-21

Mendes RR, Tirapegui J. Physical exercise, creatine and nutrition: a review. Rev Bras Cienc Farm, 1999; 35(2): 195-209

Mihic S, MacDonald JR, McKenzie S, Tarnopolsky MA. Acute creatine loading increases fat-free mass, but does not affect blood pressure, plasma creatinine, or CK activity in men and women. Med Sci Sports Exerc, 2000; 32: 291-296

Nath KA, Balla G, Verceliotti GM, Balla J, Jacob HS, Levitt MD, Rosenberg ME. Induction of heme oxygenase is a rapid protective response in rhabdomylysis in the rat. J Clin Invest, 1992; 90: $267-270$

Newsholme P, Procopio J, Ramos Lima MM, Pithon-Curi TC, Curi R. Glutamine and glutamate: their central role in cellmetabolism and function. Cell Biochem Funct, 2003; 21: 1-9

Okudan N, Gokbel H. The effects of creatine supplementation on performance during the repeated bouts of supramaximal exercise. J Sports Med Phys Fitness, 2005; 45(4): 507-11

Rogero MM, Tirapegui J. Nutritional aspects of glutamine and physical activity. Revista da Sociedade Brasileira de Alimentação e Nutrição, 2003; 25: 87-112

Sarti MA, Monfort M, Fuster MA, Villaplana LA. Muscle Activity in Upper and Lower Rectus Abdominus During Abdominal Exercises. Arch Phys Med Rehabil, 1996; 77: 1293-1297

Scott SL, Docherty D. Acute effects of heavy preloanding on vertical and horizontal jump performance. $J$ Strength Cond Res, 2004; 18(2): 201-205

Terjung RL, Clarkson P, Eichner ER, Greenhaff PL, Hespel PJ, Israel RG, Kraemer WJ, Meyer RA, Spriet L, Tarnopolsky MD, Wagenmakers AJM, Williams MH. American College of Sports Medicine round table. The physiological and health effects of oral creatine supplementation. Med Sci Sports Exerc, 2000; 32(3): 706-717

Van Loon FP, Banik AK, Nath SK, Patra FC, Wahed MA, Darmaun D, Desjeux JF, Mahalanabis D. The effect of L-glutamine on salt and water absorption: a jejunal perfusion study in cholera in humans. Eur J Gastroenterol Hepatol, 1996; 8: 443-448 
Volek JS, Duncan ND, Mazzetti SA, Staron RS, Putukian M, Gomez AL, Pearson DR, Fink WJ, Kraemer WJ. Performance and muscle fiber adaptations to creatine supplementation and heavy resistance training. Med Sci Sports Exerc, 1999; 31(8): 1147-56

Williams MH, Kreider RB, Branch JD. Creatine. São Paulo: Manole; 2000

Wright GA, Grandjean PW, Pascoe DD. The effects of creatine loading on thermoregulation and intermittent sprint exercise performance in a hot humid environment. J Strength Cond Res, 2007; 21(3): 655-660

Ziegler TR, Benfell K, Smith RJ, Young LS, Brown E, Ferrari-Baliviera E, Lowe DK, Wilmore DW. Safety and metabolic effects of L-glutamine administration in humans. J Parenter Enteral Nutr, 1990; 14(4 Suppl): 137S-146S

\section{Corresponding author:}

\section{Nuno Domingos Garrido}

Department of Sport Sciences, University of Trás-os-Montes and Alto Douro, Vila Real, Portugal

Universidade de Trás-os-Montes e Alto Douro, Complexo Desportivo da UTAD, 5000-000 Vila Real,

Portugal

Phone: +351 259350877

Fax: +351330168

E-mail: ngarrido@utad.pt 